\title{
Higher Education for Students with Autism, Using Net Promoter Score to Assess Parents Satisfaction
}

\author{
Wajdi Ahmed Wazzan \\ Department of Industrial Engineering, King Abdulaziz University, Jeddah, KSA \\ Email: wwazzan@kau.edu.sa
}

How to cite this paper: Wazzan, W. A. (2019). Higher Education for Students with Autism, Using Net Promoter Score to Assess Parents Satisfaction. Creative Education, 10, 2495-2503.

https://doi.org/10.4236/ce.2019.1011177

Received: November 1, 2019

Accepted: November 19, 2019

Published: November 22, 2019

Copyright $\odot 2019$ by author(s) and Scientific Research Publishing Inc. This work is licensed under the Creative Commons Attribution International License (CC BY 4.0).

http://creativecommons.org/licenses/by/4.0/

\begin{abstract}
This study aims to present the experience of a large public university, King Abdulaziz University, Jeddah, Saudi Arabia, in teaching students with Autism. We needed to assess the overall effect of teaching method, programs, parent's contribution, and student's involvement on the success of the university in teaching students with Autism Spectrum Disorder (ASD) using a single measure, the Net Promoter Score (NPS). We have received encouraging feedback from students' families using the NPS to measure their general satisfaction with the educational process of their children. This paper also discusses the positive impact of this experience on the University; in terms of opening the door to the acceptance of students with Autism. This study represents a unique attempt to allow Autism students to continue their higher education. The paper discusses a theoretical framework on the disability of Autism in terms of definition, characteristics and prevalence. The study presents the experience of teaching autistic students and discusses the nature of the challenges faced by the students in terms of study and adaptation to the academic community in general. This study also discusses the adaptive strategies adopted by the students in overcoming all obstacles and problems encountered in their studies at the Faculty of Tourism. This experiment led to the Tourism Faculty promise to allocate $10 \%$ of its seats for students with special needs.
\end{abstract}

\section{Keywords}

Autistic, NPS, Higher Education for Special Needs, Human Factors

\section{Introduction}

King Abdulaziz University (KAU) has a large number of people with special 
needs among its students, staff and faculty members. The university seeks to provide all services to help them perform their tasks easily, by providing an ideal university environment and easy access for all. The University has endeavored to be in the interests of all and ensure the independence and empowerment of persons with disabilities, to get the same opportunities at higher education like all other students, in accordance with international agreements signed by Saudi Arabia. Due to the attractive University environment, the number of students with special needs increased from 205 students in 2015, to 1048 in 2018, including 61 students studying their Master's and Doctoral Degrees in various majors.

The University has sought to open new fields, and diversify the available disciplines to persons with disabilities, as well as a streamlined admission process, granting admission facilities. Pilot programs are being evaluated, and the University benefits from their results in opening new areas for all types of disabilities. Examples of the following can be seen here:

- The Bachelor program in Design and Arts for female students with hearing impairment; so far running in its' fourth consecutive year. Based on this experience's success, in the next academic year the university shall open new disciplines majors for female students with hearing impairment at the Faculty of Home Economics, in the Department of Clothing and Textile. Work is also underway to open a computer science program for students with hearing impairment.

- Open new majors for students with visual impairment, such as law.

- A teaching experience for students with hearing impairment which was initiated in both the Faculty of Engineering and the Faculty of Computing and Information Technology.

According to Bin Talib (2003), students with ASD have limited opportunities to continue their schooling beyond secondary education in Saudi Arabia. As per university mission to diversify and include all students, the Center for Students with Special Needs' consultants considered all disciplines that students with the Autism can study, considering the needs of these students, and the characteristics of study in these disciplines. The Faculty of Tourism was selected as the first option, and the Faculty of Economics and Management as a second option.

The Faculty of Tourism was selected as the first choice for teaching students with Autism, due to the practical nature of studying in this faculty, especially the Diploma Program in Hospitality and Hotel Management, and the Bachelor of Hospitality Management. These two programs prepare graduates to work in the hotel industry. Working in hotels is considered suitable for autistic persons as it involves duties and routine daily functions and minor communications with customers. These duties include working in the kitchen, house-keeping department, etc. Most students are directed mainly to study in the Diploma Program, as it provides them with job opportunities quickly. As for students with Autism spectrum, the University communicates with them and their parents to choose between the Diploma and Bachelor, according to their aspirations for the future 
of their children.

For the Faculty of Economics and Administration, currently there are only a few students with Autism spectrum studying in it. The Center for Students with Special Needs' consultants sees their ability to study and communicate effectively with other students, and faculty members continuously monitor and evaluate their performance. Encouraging results have been received from both faculty as evident by asking to enroll more students and parents by using a simple one question to measure satisfaction with their kid's education at KAU.

\section{Research Objectives}

The main objective of this research was to evaluate the experience of enrolling limited number of students with autism in the Faculty of Tourism. Based on the success of the main objective, we wanted to extend the experience to other colleges and faculties. Furthermore, we wanted to use a simple, yet effective measure, to guage parents' satisfaction with their kids' education at KAU.

\section{Research Questions}

We wanted to answer following questions:

- Was the experiment satisfactory to the administration of the faculty of tourism?

- Can we enroll students with ASD in other faculties or colleges?

- Are the parents stratified with the education at KAU?

\section{Literature Review}

Autism can be defined as a neurodevelopmental disorder characterized by imbalance in three key areas of early childhood development, namely: social interaction, communication, and language skills (Alqurashi, 2017). Autism is also seen as a complex disorder that is ambiguous in terms of symptoms, diagnosis and its interference with other disabilities (McBride, 2017). The prevalence of Autism varies from country to country, due to the different methodologies adopted in the definition and diagnosis criteria. Autism is actively spreading and is not confined to one society or race in both sexes (Sabah, 2017). The widely accepted ratio is 1 - 250. It is also more prevalent among males than females, at 4-1 ratio (Al-Khatib et al., 2018). In 1943, Leo Kanner was the first to refer to Autism as a childhood disorder (Zureikat, 2010). A variety of terms have been used to refer to Autism: Subjectivity, Ruminative, Self-Isolation (Self-Preoccupation), Self-Psychosis, Autistic Childhood Schizophrenia, and Infantile Isolation.

There are many theories that have attempted to enlighten the society and the affected families about the causes of autism.

- Biological Theories: Interpret Autism as being a result of brain damage or cerebral neuron deficiency (Bakker et al., 2019).

- Hereditary \& Genetic Theories: Autism has a positive correlation between siblings and relatives, which indicates that a heritable hypothesis may be ac- 
curate. Chromosome and gene abnormalities in early childhood may also cause Autism (Heward, 2012). Studies conducted on identical twins, where one has been diagnosed with Autism, indicate that in $96 \%$ of cases, both twins have Autism. Since they share the same, identical, genetic material these studies confirm that there is a high possibility that Autism is a genetic disorder (Al-Qadi, 2010).

- Biochemical Theories: This hypothesis is based on the assumption of defects in some neurotransmitters, such as serotonin, dopamine, and neuropeptides; as the biochemical imbalances in these transmitters can lead to adverse effects in mood, memory, hormone secretion, regulation of body heat, and pain perception (Al-Khatib et al., 2018).

- Metabolic Theories: This theory assumes that Autism may result from the presence of exogenous peptide (from food) that affects the neurotransmitter within the central nervous system. This effect may be the impact of the peptides present and active in the nervous system, which may lead to disturbance in internal processes. These peptides are formed when incomplete decomposition of certain foods containing gluten; such as wheat, barley, oats, and casein found in milk and dairy products (Kiki, 2011).

- Virus \& Vaccination Hypothesis: This hypothesis refers to the failure of the immune system to produce antivirals, and vaccines given to children, especially the triple viral vaccine (MMP). The main reason for the association with this particular vaccine is the timing of the vaccine, which is carried out at the child's reaching the age of one year. This in turn corresponds to the beginning of the child's verbal abilities' progress (some autistic children lose their verbal/speech abilities between 18 and 20 months) (Kiki, 2011).

- Environmental Pollution Hypothesis: This theory is based primarily on the consistent observation that poisoning with heavy metals; such as lead and mercury, causes brain damage, especially in children's developmental stage (Kiki, 2011).

- Theory of Mind: The Theory of Mind is one of the fundamental abilities that distinguish human actions from other creatures; by virtue of which he is able to fully manifest mental states; such as beliefs, desires, intentions, emotions, imagination. Any impotence in these abilities inevitably leads to a deficit in social skills and communication (Mahmoud, 2017).

\section{Characteristics of Autistic Persons}

People diagnosed with Autism have many prevailing social characteristics. According to Shukukani and Samadi (2018), people diagnosed with autism have difficulties forming and maintaining social relations with their peers, although they may be better connected with their parents, caregivers, and other people who can provide for their needs also. They also suffer from a clear deficit in imitation ability. Bakker et al., (2019) emphasize that autistic kids don't feel the need of help from others in different circumstances and usually avoid social 
play; preferring to play alone, and when playing with other children they treat them as tools. They tend to have severe weakness and inability to make friends (Mackay et. al., 2017).

The inability to communicate effectively with others is an important characteristic of autistic persons and may greatly hinder their ability to learn. According to (Omnya, 2018), they suffer from lack of speech development entirely, and sometimes replacing it with sign language. This characteristic is the most noticeable sign of autism in more than half of students diagnosed with Autism. Additionally, they have weakness in language development such as repeating certain sentences, incomprehensible words, and the echo of the sounds he or she hears, at inappropriate times and places. This problem is prevalent among almost a quarter of autistic children (Bakker et al., 2019). The lack of proper communication is evident in their inability to properly utilize language when needing to move from one topic to another, and the inability to interpret sound tones and physical expressions (Durkin, 2017). As well as reversing pronouns (you instead of me, and vice versa), little sensitivity to grammar errors, and distorted understanding of words that evoke emotions (Omnya, 2018). Many are diagnosed what is known as Echolalia; the repetition of the sounds they hear around them, be it instantaneous or after several hours or days (Bakker et al., 2019).

Some other characteristics in behavior, interests, and activities may include extreme isolation, weakness in visual communication, avoiding direct eye contact, attachment and connection to specific and abnormal objects (toys, etc.), focusing attention on specific activities for an extended periods of time, repeated stereotyped behaviors, and collecting and keeping objects (Shukukani \& Samadi, 2018). Finally, an important characteristic of autistic persons is the rejection of any change in routine; he or she gets angry and tense when there is a change in his daily life; a slight change in his clothes, toothbrush, or meal time can lead to tension, anger and crying (Al Assal, 2013; Aitken, 2013).

Designing a program of study for autistic students requires careful consideration of characteristics of those students and proper cooperation between different parties: educators, parents, support centers, and students to overcome any obstacles during the course of study.

\section{Methodology}

This research uses qualitative measures to obtain the main objectives. First, direct communication with the faculty of tourism was open to assess the progress of students during their course of study. Second, contacting corresponding parents to assess their satisfaction uses the net promoter score.

\subsection{Participants}

The experiment was initiated with one student at the Faculty of Tourism. At the beginning of his studies, the student faced many issues, including communication and homework. The Center for Student with Special Needs communicated 
with the student's family and discovered some negligence from their side in following up with the student. The Center was able to convince the family that the educational process could not succeed without full cooperation between the student, his family and faculty members. The Center also continuously communicated with the faculty members to provide them with adequate information regarding the characteristics and methods of teaching this student needs, as well as communication with the student's parents. Another noteworthy item is that other students at the program played a vital role in helping and assisting the autistic students. The amount of support from students was amazing for the center and educators. All these combined efforts have greatly improved the student's performance, and he was able to graduate as the first student with ASD.

The following year, four students were admitted, and their performance overall was much better due to the increase of faculty members' experience in how to deal with these students, as well as the role of the Center for Students with Special Needs in effective and continuous communication with students' families. These students are expected to graduate at the end of the academic year 2019-2020. Two students were also accommodated and admitted to the Faculty of Economics and Administration, and are expected to graduate in 2022. Another student was also accommodated and admitted to the Faculty of Environmental Designs for the academic year 2018-2019. In the next academic year 2019-2020, 8 students have applied to the program, and their cases are being studied in preparation for their admittance to the University. A total of 8 students were used in this study, See Table 1.

\subsection{Students Admission}

The process of students' admission is conducted according to a specific mechanism supervised by the Vice Deanship for Students with Special Needs. The Admission \& Registration Deanship transfers all university applications to the Vice Deanship for Student with Special Needs. In turn, the Center for Student with Special Needs studies each case thoroughly; including medical reports, certificates and conducts personal interviews with each student. After admittance, the Center plays a pivotal role in the communication between the Faculty and the student's family.

\subsection{Net Promoter Score}

During the experiment, we wanted a simple measure to gauge parents' satisfaction

Table 1. Participants.

\begin{tabular}{cc}
\hline College & Count \\
\hline Tourism & 5 \\
Economics & 2 \\
Environmental Studies & 1 \\
Total & $\mathbf{8}$ \\
\hline
\end{tabular}


with the program in terms of students' progress, development, and achievement. Net Promoter Score (NPS) is a powerful tool to measure customer loyalty and organization health by default (Reichheld, 2004). It is based on a simple question: How likely are you to advise a friend or colleague on this business or practice? (Medallia, 2019). In this context, we asked parents one single question "On scale from one to ten: How likely may you recommend the program to other families to enroll their children in the program?" (Figure 1).

Responses of parents were recorded into three classes:

1) Promoters (really like the program): for responses that include 9 and 10.

2) Distractors (really dislike the program): for responses from 0 to 6 .

3) Passives (satisfied but might transfer their kids to other places if exists): for responses that include 7 and 8 .

The Net Promoter Score was then calculated by subtracting the percentage of dissatisfied parents from the satisfied parents (Artz, 2017).

\section{Results}

Results for surveying parents' opinion of the programs are shown in Figure 2.

The Net Promoter Score for our experiment was $87.5 \%$. This result gives program supervisors great confidence that the program is moving in the right direction. We believe that the experiment of teaching students with Autism at King Abdulaziz University was a great success, especially leading to increased number of students with autism applying to the university, the academic progress of those students, and their integration in the educational process. Due to the unique and diverse experience that has allowed the admittance and teaching of students with Autism, in a way that helps them integrate with the rest of the

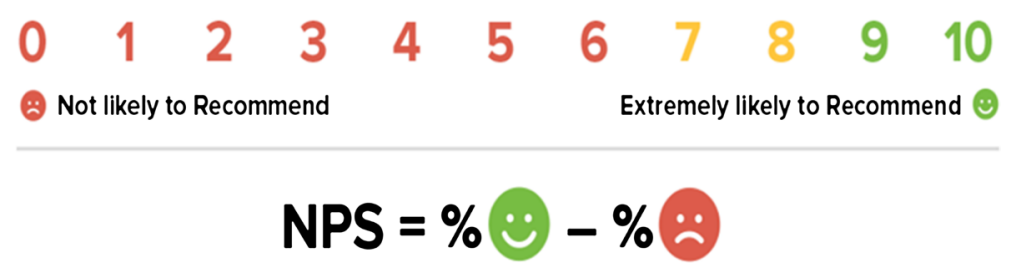

Figure 1. Net promoter score.

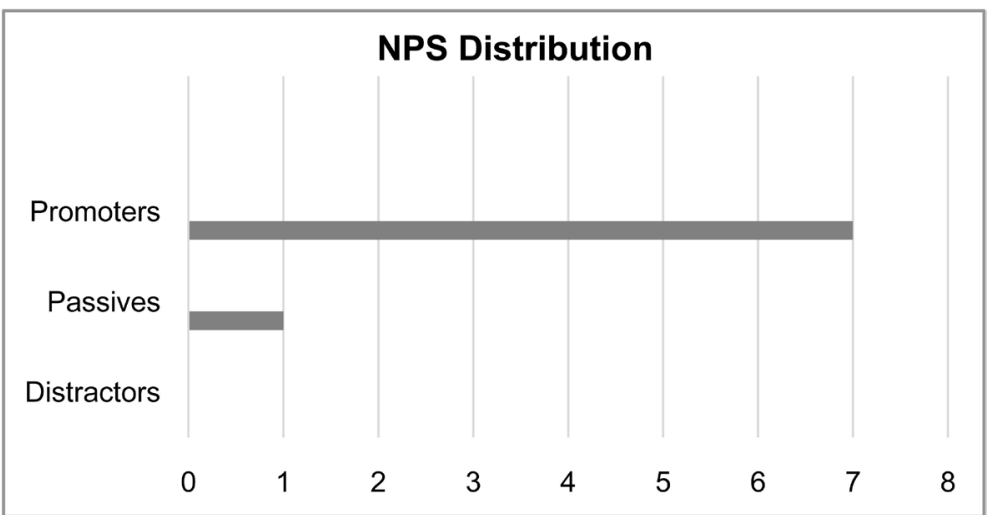

Figure 2. Distribution of responses. 
students, the Dean of the Faculty of Tourism has allocated 10\% of the Faculty's seats for students with special needs.

The experience granted the Faculty of Tourism a unique and diversified combination of students; which is very useful in developing the overall picture of both the Faculty and University, in addition to its benefits when obtaining academic accreditation. The first student graduated from the program is currently receiving recruitment training at the Saudi Airlines, in the field of catering, and will be employed upon completion of the training program. The Vice Deanship for Students with Special Needs is studying the possibility of opening more majors for these students.

\section{Conclusion}

We wholeheartedly believe that teaching students with Autism at a large public university, such as King Abdulaziz University is a worthwhile experience, and should be adopted by other higher education institutions; as the experience has shown the ability and eagerness of these students to learn, when provided with the adequate support; both academically and at home. This experiment was conducted with the participation of several segments; including faculty members and administrators, with the support of the university leaders. There is a committee for assisting students with special needs to achieve proper higher education that includes all the institutions of Gulf Cooperation Council (GCC) member states. The results of the experiment will be shared with all members of the committee in order to promote the inclusion for students with ASD into the educational process through the gulf region.

We shall conclude by expressing the cooperation between various entities at KAU succeeded in creating a sustainable program to teach and train ASD students on independence and grant them the opportunity to be active members in their society.

It should be noted however, that the available sample to conduct and evaluate the experiment was limited to 8 enrolled students at the time of reporting this work. Hence, caution should be exerted when interpreting the results of this research. Also, results are limited to students studying at specific colleges discussed in this research. Further investigation should be exercised when extending the results to a new discipline of study.

\section{Conflicts of Interest}

The author declares no conflicts of interest regarding the publication of this paper.

\section{References}

Aitken, K. (2013). The Autism Spectrum: The Changing Context of Diagnosis, Research and Practice. Good Autism Practice (GAP), 14, 80-88.

Al Assal, S. M. (2013). Autism between Talent and Disability (pp. 247-272). Jordan: Tenth Arab Scientific Conference for the Care of the Gifted and Outstanding-Criteria and In- 
dicators of Excellence (Arab Council for Gifted and Talented).

Al-Khatib, J. et al. (2018). Introduction to the Education of Students with Special Needs. Jordan, Dar Al Fikr.

Al-Qadi, K. (2010). Difficulties Preventing Parents of Autistic Individuals from Enrolling Their Children in Employment Qualified Programs, Helwan University. Educational and Social Studies, 16, 239-271.

Alqurashi, H. (2017). Teacher Education and Educating Children with Autism: Bridging the Gap between Theory and Practice in Saudi Arabia. Educational Journal, 49, 1-44. https://doi.org/10.12816/0043138

Artz, M. (2017). NPS-The One Measure You Really Need to Grow? Controlling \& Management Review, 61, 32-38. https://doi.org/10.1007/s12176-017-0002-x

Bakker, T., Krabbendam, L., Bhulai, S., \& Begeer, S. (2019). Background and Enrollment Characteristics of Students with Autism in Higher Education. Research in Autism Spectrum Disorders, 67, Article ID: 101424. https://doi.org/10.1016/j.rasd.2019.101424

Bin Talib, R. (2003). Report on the Autism Program at the Institute of Intellectual Education in East Riyadh, Riyadh.

Durkin, T. (2017). Autism Spectrum Disorders among US Children (2002-2010): Socioeconomic, Racial, and Ethnic Disparities. American Journal of Public Health, 107, 1818-1826. https://doi.org/10.2105/AJPH.2017.304032

Heward, W. (2012). Exceptional Children: An Introduction to Special Education. Upper Saddle River, NJ: Prentice-Hall, Inc.

Kiki, M. (2011). Behavioral Aspects of Autistic Children in the Institutes of Ghasak and Sara from the Perspective of their Parents, Mosul University. Journal of the College of Basic Education Research, 11, 76-99.

Mackay, T., Greig, A., \& Connolly, M. (2017). Autism Spectrum Disorders: A Major Dimension for Educational and Applied Psychology. Educational \& Child Psychology, 34, 6-12.

Mahmoud, M. (2017). The Effectiveness of Some Techniques of Mind Theory Tasks in Improving the Qualitative Dysfunction of Sensory Inputs in Children with Autism. Journal of the Faculty of Education, Assiut University, 33, 459-500.

McBride, D. (2017). Autism Spectrum Disorders and Higher Education 23. AURCO Journal.

Medallia (2019). Net Promoter Score Brochure. https://www.medallia.com/resource/nps-solution-brochure/

Omnya, M, L. (2018). Syntactic Profile in Children with Spectrum Disorders. The Egyptian Journal of Hospital Medicine, 73, 5783-5787.

Reichheld, F. (2004). The One Number you Need to Grow. Harvard Business Review, 81, 46-54+124.

Sabah, S. (2017). Using the TEACCH Program in Developing Sensory and Cognitive Skills for Children with Autism. International Journal of Educational Psychological Studies, 2, 332-353. https://doi.org/10.12816/0048128

Shukukani, H., \& Samadi, J. (2018). Evaluation of Autism Spectrum Disorder Programs in Jordan in the Light of Quality Control Indicators. Studies-Educational Sciences, University of Jordan, 45, 1-26.

Zureikat, I. (2010). Autism Behavior, Diagnosis and Treatment. Jordan, Amman, Dar Al Fikr. 